\title{
Survey on the indexes of health equity in the physical environment and infrastructures of Kermanshah province, Iran
}

\author{
Sohyla Reshadat ${ }^{1}$, Shahram Saeidi ${ }^{1 *}$ D , Alireza Zangeneh ${ }^{1}$, Ali Almasi ${ }^{1}$, Samira Rahimi Naderi ${ }^{2}$, Ramin Teimouri ${ }^{3}$, \\ Raziyeh Teimouri ${ }^{4}$, Kobra Gholami Kiaee ${ }^{5}$ and Mehdi Khezeli ${ }^{1}$
}

\begin{abstract}
Background: Health equity is directly associated with the proper distribution of resources, the existence of infrastructures, and the balanced physical environment. The present study aimed to survey the indexes of health equity in the physical environment and infrastructures of Kermanshah province based on the national indexes.

Results: The results revealed that access to transportation, health centers, solid waste management, and green and sports per capita had the least distance from the negative ideal whereas the noise pollution index had the greatest distance. However, house hygiene and air pollution indexes were within the negative and positive ideal ranges.

Conclusions: The health equity indexes were not distributed equitably across counties and geographical regions of Kermanshah province.
\end{abstract}

Keywords: Health equity, Environment, Index, Geographic Information Systems

\section{Introduction}

Nowadays, governments by providing health services and adequate and timely care as well as equitable distribution of services can affect the community's well-being and health. It should be noted that providing the best healthcare alone is not sufficient [1]. Some experts define health equity as "lack of systematic differences in health means creating equal opportunities for health and reducing health differences to the lowest possible level" [2]. Health equity implies that all segments of the society should ideally have a fair chance of benefiting from services and financing to achieve their potential full health. Establishing health equity relates with health determinants and has special complexity due to numerous dimensions and effects, causing officials and managers in

\footnotetext{
* Correspondence: SaediShahram@yahoo.com

${ }^{1}$ Social Development \& Health Promotion Research Center, Health Institute,

Kermanshah University of Medical Sciences, Kermanshah, Iran

Full list of author information is available at the end of the article
}

this regard to face the complex and major challenges. In response to these concerns, the Commission for Social Determinants of Health was established in the World Health Organization (WHO), through which some recommendations were presented to develop and monitor rights to good health at local, national, and international levels [3].

Recently, to assess gap in the health status of urban population and its determinants, a tool called "responsiveness and justice measurement in urban health" has been developed by the Health Development Center of the $\mathrm{WHO}$ which is used in Kobe, Japan [4, 5]. After designing this tool, the Tehran municipality announced to the WHO Regional Office for the Eastern Mediterranean (EMRO) its readness to investigate and measure health equity as a pilot study in Tehran in 2007. The outcome of the efforts of this working group incorporated the proposal of six areas instead of four areas within Iran, including infrastructure and physical environment, human and social 
development, economic development, governance, nutrition, and health [6].

One of the levels for national and regional planning is awareness of the capabilities of different provinces and their counties. Moreover, evidence has shown that Geographic Information System (GIS) has always been one of the most useful tools in this respect [7].

The destruction of the infrastructures of Kermanshah province because of the 8-year war between Iran and Iraq caused this province to fall behind development compared to other provinces. This issue led to the backwardness of this province and many other detrimental consequences including the settlement of a large part of war veterans of the province in the capital city of Kermanshah and its excessive population growth. The main impact of this trend was the interruption and failure in the system of service distribution, and subsequently led to the failure of citizens' adequate access to such services [8]. On the other hand, Kermanshah is also faced with other problems such as poverty, high general fertility in some regions, AIDS, cancer [9], and economic loss in the areas of animal husbandry, agriculture, farming, and gardening due to air pollution (dust phenomenon).

Air pollution occurs in Kermanshah like other big cities, which ends to 500 as hazardous air quality that necessitates avoidance of outdoor activities. The Air Quality Index (AQI) is an important tool to assess air quality and evaluate its effects on health. AQI is determined by six major pollutants as important criteria: ozone $\left(\mathrm{O}_{3}\right)$, sulfur dioxides $\left(\mathrm{SO}_{2}\right)$, inhalable particles $\left(\mathrm{PM}_{10}\right)$, fine particulate matter $\left(\mathrm{PM}_{2.5}\right)$, nitrogen dioxides $\left(\mathrm{NO}_{2}\right)$, and carbon monoxide (CO) [10]. The AQI scale is in the range of 0 to 500 to qualify the overall quality of the air into six levels in different colors (good in green, moderate in yellow, lightly polluted in orange, moderately polluted in red, heavily polluted in purple, and severely polluted in maroon). These levels indicate air pollution overall effects on human health and decent reference for people's outdoor activities in a numerical pattern. A low number means good air quality, while an increasing number means worsening air quality, for example values over 300 represent hazardous air quality which is the health warning of emergency condition and everyone is more likely to be affected [11]. The present study aimed to survey the indexes of health equity in the physical environment and infrastructures of Kermanshah province based on the national indexes.

\section{Methods}

\subsection{Design and setting}

This cross-sectional study was performed using quantitative models, based on the national indexes codified by the Ministry of Health and Medical Education of Iran in 2016. The geographic area of this study was Kermanshah province, western Iran, and its statistical population was all of 14 counties including Kermanshah, Eslamabad-e Gharb, Paveh, Harsin, Kangavar, Sonqor, Javanrud, Ravansar, Gilan-e Gharb, Sahneh, Qasr-e Shirin, and Sarpol-e Zahab, Dalahu, and Salas-e Babajani.

Data was collected about eight indexes related to the assessment of equity in the area of physical environment and infrastructures, codified by the Ministry of Health and Medical Sciences [6] and based on the study conducted in Kobe, Japan [5]. These indexes were as follows:

1) The data on house hygiene (the percentage of households with waste disposal systems, sanitary toilets, and access to public drinking water network) were collected through the statistics provided by health center of Kermanshah.

2) The data on air pollution (dust) including the percentage of clean days in the year were collected from the meteorological organization of Kermanshah.

3) The data on noise pollution by industries were collected from the Industry, Mine and Trade Organization of Kermanshah province.

4) The data on access to public transportation was collected from the municipalities of counties.

5) The data on access to health centers (including primary health care).

6) The data on solid waste management (the status of waste management in urban areas, hospitals, and villages) was collected from the Health Network in each county.

7) The data on green space per capita in the province were collected from the municipalities of counties.

8) The data on sports per capita were collected from the Sport Department of Kermanshah province.

\subsection{Data collection}

The required information was collected through documentary methods from the related departments in Kermanshah province. Additionally, the demographic data of each county were collected through the statistical blocks of the Official Statistics Center of Iran. Moreover, the latest population statistics (the demographic data of 2016) published by the Statistical Centre of Iran were used as the basis of the study.

\subsection{Data analysis}

In the first step, data about the studied eight indexes were collected. Then, the Technique for Order of Preference by Similarity to Ideal Solution (TOPSIS) that is a multi-criteria decision analysis method was used. This technique, as one of the best multi-criteria decisionmaking models which are used extensively, was first 
proposed by Hawang and Yoon in 1981 [12]. In this method, $\mathrm{m}$ alternatives are evaluated by $\mathrm{n}$ criteria. This technique is based on the notion that the selected alternative should have the furthest distance from the negative ideal solution. It is assumed that the utility of each index is uniformly increasing or decreasing. Problem-solving using TOPSIS includes the following steps:

1) Formation of data matrixes based on an alternative (counties) and $\mathrm{m}$ indexes (the applied indexes in the research),

2) Creating the normalized decision matrix.

3) Establishing the weighted normalized matrix (V): the normalized matrix $(\mathrm{N})$ is multiplied by the diagonal matrix of weights (Wn).

4) Determining the ideal positive solutions (determination of the maximum value for each of the weighted standardized indicators) and negative solutions (determination of the minimum value for each of the weighted standardized indicators).

5) Calculating the distance of each alternative from the positive ideals and negative ideals.

6) Determining the relative proximity of alternatives to the ideal solution. $\mathrm{Cl}_{\mathrm{i}}=\frac{\mathrm{d}^{-}}{\mathrm{d}^{-}+\mathrm{d}^{+}}$

7) Ranking the alternatives in ascending order by the value of Consistency Index (CI): the alternatives selected must have the shortest distance from the positive ideal solution and the farthest from the negative ideal solution. If the $\mathrm{CI}$ value is closer to one, the situation is better.

Then, the priority map of counties was drawn in terms of the indexes of health equity using the Arc/GIS 10.6 Software.

It is worth noting that the Shannon's Entropy Method was used to weighting in TOPSIS because knowing the relative weights of indexes is an effective step in the problem-solving process when it comes to multi-criteria decision making. Moreover, $K$ is a positive constant, and the $P$-value (normalized matrix) was calculated for each i (alternative) and $\mathbf{j}$ (index). TOPSIS method was used in the TOPSIS-SOLVER Software. Finally, the results of eight indices were presented in proper maps to display the condition of counties using the Arc/GIS 10.6 Software.

\section{Results}

As shown in Table 1 and Fig. 1a, all counties obtained further than $95 \%$ of scores in house hygiene index. All households residing in Kermanshah province had access to safe drinking water and standard sanitary toilets. Also, household sanitary sewage disposal was lower than $90 \%$ in only three cities, including Dalahu (88.8\%), Paveh (87.5\%), and Qasr-e Shirin (85.3\%).
The results of solid waste management in urban areas showed that seven cities had provided more than $90 \%$ of the proper waste management. Table 1 and Fig. 1b showed that Salas-e Babajani and Kermanshah counties had the lowest and highest levels of urban proper waste management (85\% and 95\%, respectively). In the rural waste management index, only in Paveh County, more than $80 \%$ of proper waste management was provided, and in other cities, it was less than $70 \%$ (86\% and $51 \%$ in Paveh and Ravansar, respectively). All counties had proper waste management in hospitals and inpatient treatment centers.

According to Table 2 and Fig. 1c, Paveh and Sarpol-e Zahab had the most and the fewest percentage of clean days, an indicator of lacking air pollution $(97.53 \%$ vs. $91.2 \%$, respectively).

The results showed that access to health centers was more than $80 \%$ in only one county and less than $60 \%$ in other cities. Figure 1d shows that Kermanshah (80.93\%) and Ravansar (5.36\%) counties had the highest and least access to health centers, respectively. Moreover, Ravansar and Harsin according to Fig. 1e had the highest and lowest levels of noise pollution $(51 \%$ and $0.4 \%$, respectively). Furthermore, Dalahu (87\%) and Kermanshah (25\%) counties had the highest and least access to public transportation, respectively (Fig. 1f). According to Fig. 1g, Sarpol-e Zahab and Ghasr-e-Shirin had the highest and lowest green space per capita (14.66 and $2.66 \mathrm{~m}^{2}$, respectively), and Fig. 1h showed that Ghasr-e-Shirin $\left(4.56 \mathrm{~m}^{2}\right)$ and Kermanshah $\left(0.61 \mathrm{~m}^{2}\right)$ had the highest and lowest values of sports per capita.

The results demonstrated that Javanrood, Ghasr-eshirin, Harsin, Sahneh, and Dalahoo were ranked one to five according to the TOPSIS. Regarding the counties of Kermanshah, Salas-e Babajani, Paveh, Gilan-e Gharb, and Songhor were ranked sixth to tenth, respectively. Moreover, the counties of Islamabad, Kangavar, Sarpol-e Zahab, and Ravansar held the 11th to 14th positions, respectively (Tables 2, 3, 4, 5, 6 and 7).

As shown in Table 5, comparison of 8 indicators showed that access to transportation (0.0029), access to health centers (0.0057), solid waste management (0.0001), green space per capita (0.0098), and sports per capita (0.0139) had the shortest distance with a negative ideal. On the other hand, the noise pollution index had the longest distance from the negative ideal (0.2925), and the house hygiene and air pollution indices were between the two negative and positive ideals.

\section{Discussion}

This study aimed to survey the indexes of equity in the physical environment and infrastructures of Kermanshah province based on the national indexes. 


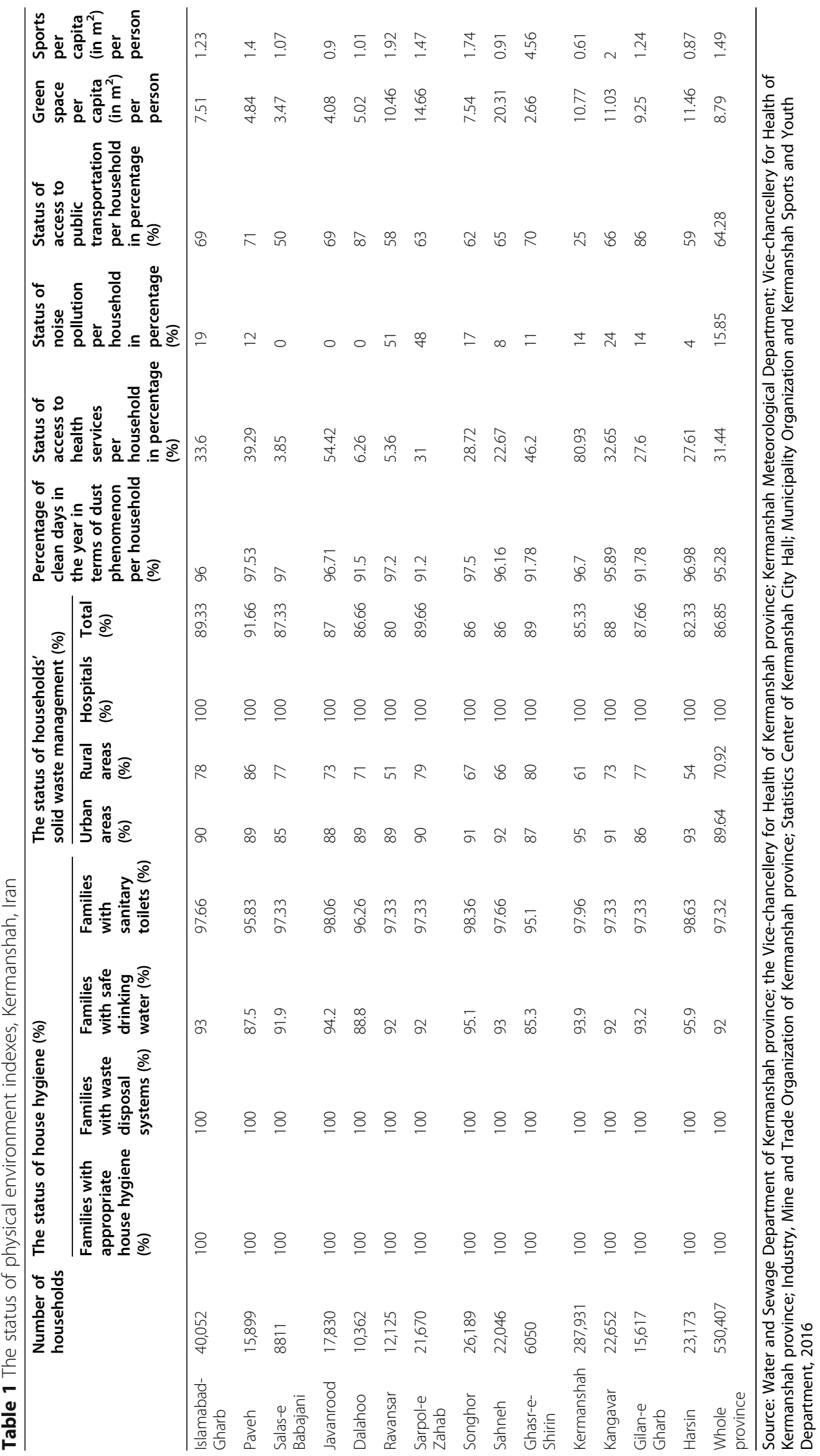



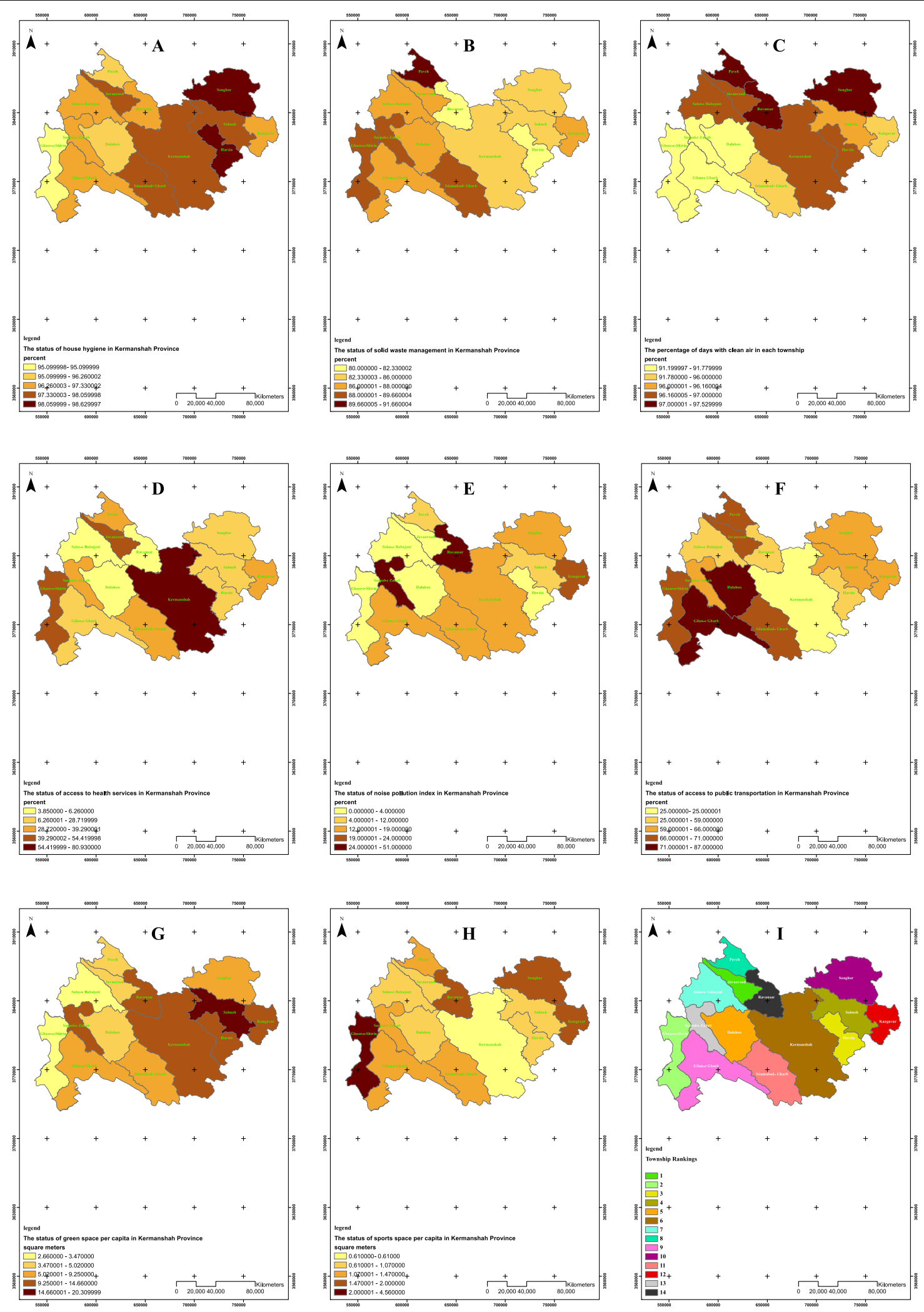

Fig. 1 The map of the status of health equity in physical and infrastructure indexes and counties ranking in Kermanshah province in 2016 using GIS 
Table 2 The indexes of equity in physical environment and infrastructures across Kermanshah province, Iran

\begin{tabular}{|c|c|c|c|c|c|c|c|c|}
\hline Counties & $\begin{array}{l}\text { House } \\
\text { hygiene (\%) }\end{array}$ & $\begin{array}{l}\text { Air pollution } \\
(\%)\end{array}$ & $\begin{array}{l}\text { Noise pollution } \\
\text { from industries } \\
\text { (\%) }\end{array}$ & $\begin{array}{l}\text { Access to public } \\
\text { transportation (\%) }\end{array}$ & $\begin{array}{l}\text { Access to } \\
\text { health } \\
\text { centers (\%) }\end{array}$ & $\begin{array}{l}\text { Solid waste } \\
\text { management } \\
(\%)\end{array}$ & $\begin{array}{l}\text { Green } \\
\text { space }\left(\mathrm{m}^{2}\right)\end{array}$ & $\begin{array}{l}\text { Sports per } \\
\text { capita }\left(\mathrm{m}^{2}\right)\end{array}$ \\
\hline Kermanshah & 97.96 & 96.7 & 14 & 25 & 80.93 & 85.33 & 10.77 & 0.61 \\
\hline Islamabad- Gharb & 97.66 & 96 & 19 & 69 & 33.6 & 89.33 & 7.51 & 1.23 \\
\hline Harsin & 98.63 & 96.98 & 4 & 59 & 27.61 & 82.33 & 11.46 & 0.87 \\
\hline Kangavar & 97.33 & 95.89 & 24 & 66 & 32.65 & 88 & 11.03 & 2 \\
\hline Songhor & 98.36 & 97.5 & 17 & 62 & 28.72 & 86 & 7.54 & 1.74 \\
\hline Sahneh & 97.66 & 96.16 & 8 & 65 & 22.67 & 86 & 20.31 & 0.91 \\
\hline Javanrood & 98.06 & 96.71 & 0 & 69 & 54.42 & 87 & 4.08 & 0.9 \\
\hline Sarpol-e Zahab & 97.33 & 91.2 & 48 & 63 & 31 & 89.66 & 14.66 & 1.47 \\
\hline Paveh & 95.83 & 97.53 & 12 & 71 & 39.29 & 91.66 & 4.84 & 1.4 \\
\hline Gilan-e Gharb & 97.33 & 91.78 & 14 & 86 & 27.6 & 87.66 & 9.25 & 1.24 \\
\hline Ravansar & 97.33 & 97.2 & 51 & 58 & 5.36 & 80 & 10.46 & 1.92 \\
\hline Dalahoo & 96.26 & 91.5 & 0 & 87 & 6.26 & 86.66 & 5.02 & 1.01 \\
\hline Ghasr-e-Shirin & 95.1 & 91.78 & 11 & 70 & 46.2 & 89 & 2.66 & 4.56 \\
\hline Salas-e Babajani & 97.3 & 97 & 0 & 50 & 3.85 & 87.33 & 3.47 & 1.07 \\
\hline
\end{tabular}

The results showed that the indexes of access to transportation, access to health centers, solid waste management, and green and sports per capita had the least distance from the negative ideal whereas the noise pollution index had the greatest distance. However, house hygiene and air pollution indexes were within the negative and positive ideal ranges. Hence, it can be concluded that the status of equity in the physical environment and infrastructures in Kermanshah province was unbalanced.

Additionally, the findings of the present study on better conditions of eight indexes in some counties indicated the lack of sustainable development in Kermanshah province, even if the standard per capita was similar between counties. It is well known that any development that is not comprehensive and not following a systematic and integrated model cannot be sustainable [13]. The results of a study performed by Maleki et al. in Khuzestan province showed the lack of spatial equity in distribution of facilities and health services across its counties [13].

The results of the present study showed that the majority of households had proper house hygiene, the highest

Table 3 Standardized matrix of indexes

\begin{tabular}{|c|c|c|c|c|c|c|c|c|}
\hline Counties & $\begin{array}{l}\text { House } \\
\text { hygiene }\end{array}$ & Air pollution & $\begin{array}{l}\text { Noise pollution } \\
\text { from industries }\end{array}$ & $\begin{array}{l}\text { Access to public } \\
\text { transportation }\end{array}$ & $\begin{array}{l}\text { Access to } \\
\text { health centers }\end{array}$ & $\begin{array}{l}\text { Solid waste } \\
\text { management }\end{array}$ & $\begin{array}{l}\text { Green } \\
\text { space }\end{array}$ & $\begin{array}{l}\text { Sports } \\
\text { per capita }\end{array}$ \\
\hline Kermanshah & 0.2691 & 96.7 & 14 & 25 & 80.93 & 85.33 & 10.77 & 0.61 \\
\hline Islamabad-Gharb & 0.2682 & 96 & 19 & 69 & 33.6 & 89.33 & 7.51 & 1.23 \\
\hline Harsin & 0.2709 & 96.98 & 4 & 59 & 27.61 & 82.33 & 11.46 & 0.87 \\
\hline Kangavar & 0.2673 & 95.89 & 24 & 66 & 32.65 & 88 & 11.03 & 2 \\
\hline Songhor & 0.2702 & 97.5 & 17 & 62 & 28.72 & 86 & 7.54 & 1.74 \\
\hline Sahneh & 0.2682 & 96.16 & 8 & 65 & 22.67 & 86 & 20.31 & 0.91 \\
\hline Javanrood & 0.2693 & 96.71 & 0 & 69 & 54.42 & 87 & 4.08 & 0.9 \\
\hline Sarpol-e Zahab & 0.2673 & 91.2 & 48 & 63 & 31 & 89.66 & 14.66 & 1.47 \\
\hline Paveh & 0.2632 & 97.53 & 12 & 71 & 39.29 & 91.66 & 4.84 & 1.4 \\
\hline Gilan-e Gharb & 0.2673 & 91.78 & 14 & 86 & 27.6 & 87.66 & 9.25 & 1.24 \\
\hline Ravansar & 0.2673 & 97.2 & 51 & 58 & 5.36 & 80 & 10.46 & 1.92 \\
\hline Dalahoo & 0.2644 & 91.5 & 0 & 87 & 6.26 & 86.66 & 5.02 & 1.01 \\
\hline Ghasr-e-Shirin & 0.2612 & 91.78 & 11 & 70 & 46.2 & 89 & 2.66 & 4.56 \\
\hline Salas-e Babajani & 0.2673 & 97 & 0 & 50 & 3.85 & 87.33 & 3.47 & 1.07 \\
\hline $\begin{array}{l}\text { Shannon's Entropy } \\
\text { of weighting }\end{array}$ & 0.0001 & 0.0003 & 0.4753 & 0.0287 & 0.207 & 0.0006 & 0.1378 & 0.1502 \\
\hline
\end{tabular}


Table 4 Standardized weight matrix of indexes

\begin{tabular}{lllllllll}
\hline Counties & $\begin{array}{l}\text { House } \\
\text { hygiene }\end{array}$ & Air pollution & $\begin{array}{l}\text { Noise pollution } \\
\text { from industries }\end{array}$ & $\begin{array}{l}\text { Access to public } \\
\text { transportation }\end{array}$ & $\begin{array}{l}\text { Access to } \\
\text { health centers }\end{array}$ & $\begin{array}{l}\text { Solid waste } \\
\text { management }\end{array}$ & $\begin{array}{l}\text { Green } \\
\text { space }\end{array}$ & $\begin{array}{l}\text { Sports } \\
\text { per capita }\end{array}$ \\
\hline Kermanshah & 0 & 0.0001 & 0.0803 & 0.0029 & 0.1206 & 0.0002 & 0.0398 & 0.0139 \\
Islamabad-Gharb & 0 & 0.0001 & 0.109 & 0.008 & 0.0501 & 0.0002 & 0.0278 & 0.028 \\
Harsin & 0 & 0.0001 & 0.0229 & 0.0069 & 0.0411 & 0.0002 & 0.0424 & 0.0198 \\
Kangavar & 0 & 0.0001 & 0.1376 & 0.0077 & 0.0487 & 0.0002 & 0.0408 & 0.0455 \\
Songhor & 0 & 0.0001 & 0.0975 & 0.0072 & 0.0428 & 0.0002 & 0.0279 & 0.0396 \\
Sahneh & 0 & 0.0001 & 0.0459 & 0.0076 & 0.0338 & 0.0002 & 0.0751 & 0.0207 \\
Javanrood & 0 & 0.0001 & 0 & 0.008 & 0.0811 & 0.0002 & 0.0151 & 0.0205 \\
Sarpol-e Zahab & 0 & 0.0001 & 0.2753 & 0.0073 & 0.0462 & 0.0002 & 0.0542 & 0.0334 \\
Paveh & 0 & 0.0001 & 0.0688 & 0.0083 & 0.0586 & 0.0002 & 0.0179 & 0.0318 \\
Gilan-e Gharb & 0 & 0.0001 & 0.0803 & 0.01 & 0.0411 & 0.0002 & 0.0342 & 0.0282 \\
Ravansar & 0 & 0.0001 & 0.2925 & 0.0068 & 0.008 & 0.0001 & 0.0387 & 0.0437 \\
Dalahoo & 0 & 0.0001 & 0 & 0.0101 & 0.0093 & 0.0002 & 0.0186 & 0.023 \\
Ghasr-e-Shirin & 0 & 0.0001 & 0.0631 & 0.0081 & 0.0689 & 0.0002 & 0.0098 & 0.1037 \\
Salas-e Babajani & 0 & 0.0001 & 0 & 0.0058 & 0.0057 & 0.0002 & 0.0128 & 0.0243 \\
\hline
\end{tabular}

level was in Harsin and the lowest in Ghasr-e-Shirin, which was consistent with the results of a study conducted by Ghadermarzy et al. [14]. Given that Ghasr-eShirin is located in the border area of Iran with Iraq and was the first point attacked by Iraqi army in the 8-year Iran-Iraq war, it is likely that damages on its infrastructures, late reconstruction of destroyed houses, in addition the long distance from the province center have led to the lower level of house hygiene; however, this explanation requires further studies. House hygiene indicators such as toilets and sewage are important because they have a direct impact on the prevalence of infectious diseases and the physical health of family members $[15$, 16]. However, the general situation of the house hygiene index in the province was favorable.

The findings of the present study indicated that Kermanshah province had good category of Air Quality Index (AQI) around 95\% of the days of the year. Kermanshah province is exposed to air pollution only

Table 5 Positive and negative ideals

\begin{tabular}{lll}
\hline $\begin{array}{l}\text { Indexes of equity in the physical } \\
\text { environment and infrastructures }\end{array}$ & $\begin{array}{l}\text { Positive ideals } \\
(\mathbf{A}+)\end{array}$ & $\begin{array}{l}\text { Negative ideals } \\
(\mathrm{A}-\mathbf{)}\end{array}$ \\
\hline House hygiene & 0 & 0 \\
Air pollution & 0.0001 & 0.0001 \\
Noise pollution from industries & 0 & 0.2925 \\
Access to public transportation & 0.0101 & 0.0029 \\
Access to health centers & 0.1206 & 0.0057 \\
Solid waste management & 0.0002 & 0.0001 \\
Green space & 0.0751 & 0.0098 \\
Sports per capita & 0.1037 & 0.0139 \\
\hline
\end{tabular}

$5 \%$ of the days of the year, showing a downward trend compared with the statistics of 2009-2010, similar to the results of a study performed by Shamshiri et al. [17] In the last two decades, dust storms in the south and west of Iran have been a reemerging phenomenon whose number of days in previous years has been variable and affected by rainfall and air temperature $[18,19]$. Due to the increase in rainfall over the past few years in Kermanshah province [20], this increase in rainfall has probably been effective in reducing dust storm and air pollution.

Table 6 Distance from the positive and negative ideals

\begin{tabular}{lll}
\hline $\begin{array}{l}\text { Indexes of equity in the physical } \\
\text { environment and infrastructures }\end{array}$ & $\begin{array}{l}\text { Positive ideals } \\
(\mathbf{A}+)\end{array}$ & $\begin{array}{l}\text { Negative ideals } \\
(\mathbf{A}-\mathbf{)}\end{array}$ \\
\hline Kermanshah & 0.1258 & 0.2432 \\
Islamabad-Gharb & 0.1576 & 0.1903 \\
Harsin & 0.1223 & 0.2739 \\
Kangavar & 0.1694 & 0.1667 \\
Songhor & 0.148 & 0.201 \\
Sahneh & 0.1286 & 0.2568 \\
Javanrood & 0.11 & 0.3022 \\
Sarpol-e Zahab & 0.2945 & 0.0656 \\
Paveh & 0.1305 & 0.2307 \\
Gilan-e Gharb & 0.1419 & 0.2171 \\
Ravansar & 0.3212 & 0.0417 \\
Dalahoo & 0.1487 & 0.2929 \\
Ghasr-e-Shirin & 0.1045 & 0.2544 \\
Salas-e Babajani & 0.1529 & 0.2927 \\
\hline
\end{tabular}


Table 7 Township rankings using TOPSIS

\begin{tabular}{lll}
\hline Counties name & $\begin{array}{l}\text { Relative proximity } \\
\text { of alternatives (Cli) }\end{array}$ & Ranking \\
\hline Javanrood & 0.7332 & 1 \\
Ghasr-e-Shirin & 0.7088 & 2 \\
Harsin & 0.6913 & 3 \\
Sahneh & 0.6663 & 4 \\
Dalahoo & 0.6633 & 5 \\
Kermanshah & 0.6591 & 6 \\
Salas-e Babajani & 0.6568 & 7 \\
Paveh & 0.6387 & 8 \\
Gilan-e Gharb & 0.6047 & 9 \\
Songhor & 0.5759 & 10 \\
Islamabad- Gharb & 0.547 & 11 \\
Kangavar & 0.496 & 12 \\
Sarpol-e Zahab & 0.1822 & 13 \\
Ravansar & 0.1149 & 14 \\
\hline
\end{tabular}

Our findings on solid waste management showed that all hospitals in the province had recycling and disposal waste facilities. Moreover, urban and rural areas had access to solid waste management. However, there is no integrated and codified program for waste management in urban and rural areas of Kermanshah province. Also rural areas of Ravansar and Harsin counties had the poorest solid waste management, requiring the attention and effort of health authorities of Kermanshah province. This finding was consistent with the results of a study conducted by Bakhtyari et al. [21]. Studies show that access to sound waste management services is still limited in developing countries, especially in rural areas [22]. Disposal of waste in the natural environment and the lack of dumpsites are the main reasons for the low quality of waste management in rural areas [23].

Other results showed that Kermanshah and Javanrood had the highest access to health centers while Salas-e Babajani, Ravansar, and Dalahu had the lowest access (less than 10\%). This finding was consistent with the results of studies done by Sulaimany et al. [24] and Mousavi et al. [25]. This difference was very significant between the counties, which indicated a lack of geographical heterogeneity and inequality in access to health centers throughout Kermanshah province. This needs a rapid shifting in policies towards people's access to health services. Similarly, health inequity between different regions of Iran [9] and within Kermanshah province in terms of access to health services have been shown [26]. Despite the primary health care system (PHC) at the level of health houses, rural and urban health centers, and hospitals in each county, it seems that the geographical condition, relative deprivation, and lack of road development in each county has affected the existence of health service centers and people's access to the available health centers.

The results of our study showed the poor condition of sports per capita in Kermanshah province compared to the national [27] and the international standards [28]. This index was much lower in Kermanshah than provincial level. Similarly, the results of other studies have also pointed to the inappropriate distribution of sports spaces in other provinces of Iran [27, 29].

Another finding of present study indicated a significant shortage in the green space per capita in Kermanshah province compared to the global standards [30], and the value obtained is also lower than the national standards [31]. The lack of equal access to green space in the province was consistent with the results of a study conducted by Tajdar et al. [32]. The importance of access to green space has been emphasized in some other studies $[6,33]$.

Based on the results of the present study, more than $15 \%$ of the households in the province suffered from noise pollution. This statistic was calculated based on industrial-towns along with other structures [34]. The results of comparing counties demonstrated that Ravansar and Sarpol-e-Zahab had the highest and Sahneh and Harsin had the lowest percentage of noise pollution. This difference is probably due to the lack of suitability of land applications in Kermanshah province and other reasons such as the urban structure, as mentioned in other studies [34]. However, the results of this study showed that noise pollution is not limited to large and industrial cities and also exists in small cities of the province, which may be due to the activity of small technical business in the cites, development of urban housing complexes, and lack of proper land use. The problem of noise pollution is a public health challenge in all developed and developing countries, mainly due to roads, airports, industrial towns, and technical occupations $[35,36]$. The negative effects of noise pollution in the counties can be mitigated through applying land use plans and creating audio maps and comprehensive analysis of various policies at the county level.

Our findings showed that more than half of the province's population had appropriate access to public transportation. The results also indicated that Dalahu and Kermanshah counties had the highest and lowest percentages of access to public transportation, respectively, consistent with the results of study by Tajdar et al. which confirmed the differences in various regions of the province [32]. It is likely that the sudden increase in the population of Kermanshah city during the last two decades and the incompatibility of public transportation with the population is the main reason for this 
difference. That is why the urban Kermanshah monorail project was put on the agenda, but its slow progress contributed to the continued problem of public transportation in Kermanshah.

In the present study, consistent with the similar studies [32], we used the GIS to assess the environmental and physical infrastructural indexes. This indicates that geography and GIS can be applicable scientific tools in health and inequalities assessments. We also used Shannon's Entropy Method and TOPSIS for weighting and ranking. Moreover, the Arc/GIS software was used for displaying the conditions of counties similar to some other studies [37].

The results of our study demonstrated that the counties of Islamabad, Kangavar, Sarpol-e-Zahab, and Ravansar were far from the positive ideal and had the lowest ranks in terms of health equity in physical environment and infrastructure. In addition to the necessity to investigate the causes of this inequity, there is a need for scientific planning and practical measures to reduce the inequalities. This issue has become more important due to the 7.3 magnitude earthquake in 2017 in the west of Kermanshah province, especially Sarpolzahab, Islamabad, and Ravansar, which had destructive effects on physical infrastructure and health.

The imbalance in the physical environment and infrastructures in Kermanshah province means that the implemented policies have not led to health equity in the province. In studies conducted outside Iran, policy-making and planning have also been mentioned as important issues on health equity $[38,39]$. Concentration of services in urban places created bipolar areas and also led to migration from the rural to urban areas, and subsequently creating the inequity and misdistribution of services and facilities in the province. Imbalance and inequality in infrastructure is evident when we compare the counties. Javanrood and Ravansar, as two neighboring counties, have the highest and lowest rank in terms of equity in the physical environment and infrastructures, respectively. Similarly, Rezaei et al. concluded that Javanrood and Ravansar were developed and underdeveloped in terms of access to health services, respectively [40]. This finding indicates the need to precise regional planning in Kermanshah province towards balanced development in all areas.

\subsection{Study limitations}

The present study only examined the indices of physical environment and infrastructures, and the reasons for this inequity were not assessed. Hence, it is recommended that the causes of this inequity be investigated for each of the eight indexes in future studies.

\section{Conclusion}

The results of the present study revealed that the indices of health equity in physical environment and infrastructures were not distributed equitably between the counties of Kermanshah province. Accordingly, the asymmetric distribution of indexes in counties was the key factor in creating health inequity and should be considered as a challenge by planners, health managers, and policymakers. The model proposed in the present study can be used in all provinces of Iran and other developing countries.

\section{Acknowledgements \\ We would like to thank Meteorology Center of Kermanshah, Kermanshah Water and Wastewater Company; Kermanshah Sports Department; Kermanshah Municipality; Industry, Mining, and Trade Organization of Kermanshah province; Kermanshah Governorate; and Kermanshah University of Medical Sciences.}

\section{Authors' contributions}

SR and ShS conceptualized the main idea. ShS designed and analyzed. SR, ShS, ARZ, RazT, and RT interpreted the results and drafted the manuscript. All the authors take responsibility for the integrity of the work as a whole from inception to the published article. SR is the guarantor. ShS, AA, MKh, SRN, and KGK conducted the corrections, further analysis, and language editing. All the authors read and approved the final manuscript.

\section{Funding}

This study was funded by the Vice Chancellor for Research and Technology of Kermanshah University of Medical Sciences (grant number: 980463).

\section{Availability of data and materials}

Data will be available upon request.

\section{Ethics approval and consent to participate}

Approval of Research Ethics Committee (REC) of Kermanshah University of Medical Sciences was granted (code 980463). Consent to participate is not applicable. The permission and access to the data were obtained from the data holders.

\section{Consent for publication}

Not applicable.

\section{Competing interests}

The authors declare no competing interests.

\section{Author details}

${ }^{1}$ Social Development \& Health Promotion Research Center, Health Institute, Kermanshah University of Medical Sciences, Kermanshah, Iran. ${ }^{2}$ Department of Nursing, School of Nursing and Midwifery, Hamadan University of Medical Sciences, Hamadan, Iran. ${ }^{3}$ Clinical Laboratory Science, Tabriz University, Tabriz, Iran. ${ }^{4}$ Department of Art, Architecture and Design, University of South Australia, Adelaide, Australia. ${ }^{5}$ Social Determinants in Health Promotion Research Center, Hormozgan Health Institute, Hormozgan University of Medical Sciences, Bandar Abbas, Iran.

Received: 9 October 2019 Accepted: 9 February 2021

Published online: 01 April 2021

\section{References}

1. Health WCoSDo, Organization WH. Closing the gap in a generation: health equity through action on the social determinants of health: Commission on Social Determinants of Health, final report. Geneva: World Health Organization; 2008.

2. McGovern T, Ahmed A. Equity in health. In: Foundations of global health \& human rights. Gostin L, Meier B, editors. Ch 14. Oxford: Oxford University Press; 2020. Oxford: Oxford University; 2020.

3. Dehnavieh R, Mirshekari N, Ghasemi S, Goudarzi R, Haghdoost A, Mehrolhassani MH, et al. Health technology assessment: off-site sterilization. Med J Islam Repub Iran. 2016;30(345):1-11. 
4. Chiotan C, Costongs C. Can we build on existing information systems to monitor health inequities and the social determinants of health in the EU: EuroHealthNet; 2010.

5. World Health Organization (WHO). Urban health equity assessment and response tool (Urban HEART). Kobe: WHO Centre for Health Development; 2010.

6. Beheshtian M, Manesh AO, Bonakdar S, Afzali HM, Larijani B, Hosseini L, et al. Intersectoral collaboration to develop health equity indicators in Iran Iran J Public Health. 2013;42(Suppl 1):31-5.

7. AbouZahr C, Boerma T, Hogan D. Global estimates of country health indicators: useful, unnecessary, inevitable? Glob Health Action. 2017; 10(Supppl 1):4-17

8. Reshadat S, Saedi S, Zangeneh A, Ghasemi S, Gilan N, Karbasi A, et al. Spatial accessibility of the population to urban health centres in Kermanshah, Islamic Republic of Iran: a geographic information systems analysis. East Mediterr Health J. 2015;21(6):389-95.

9. Reshadat S, Saeidi S, Zangeneh AR, Khademi N, Khasi K, Ghasemi S, et al. Spatiotemporal distribution of gastrointestinal tract cancer through GIS over 2007-2012 in Kermanshah-Iran. Asian Pac J Cancer Prev. 2015;16(17):7737-42.

10. Mintz D. Technical assistance document for the reporting of daily air quality-the air quality index (AQI). Tech Research Triangle Park, US Environmental Protection Agency. 2009.

11. Liu H, Li Q, Yu D, Gu Y. Air quality index and air pollutant concentration prediction based on machine learning algorithms. Appl Sci. 2019;9(19):4069.

12. Hwang $\mathrm{CL}$, Yoon K. Methods for multiple attribute decision making. In: multiple attribute decision making. Berlin: Springer; 1981. p. 58-191.

13. Maleki S, Ahmadi R, Torabi ZA. An investigation of the spatial justice in distribution of hygienic- therapeutic facilities and services in the cities of Khuzestan province. Q Geogr J Territory. 2015;12(46):1-22.

14. Ghadermarzy $H$, Jamini $D$, Jamshidi A, Cheraghi R. Analysis of spatial inequality in rural areas based on the housing indicators of rural of Kermanshah province. J Space Econ Rural Dev. 2013;2(3):93-113.

15. Otsuka $Y$, Ushijima K, Ikemi M, Nilawati $D$, Sintawardani N, Yamauchi T. Mapping of water, sanitation, hygiene and child health in an urban slum of Indonesia. Sanit Value Chain. 2018;2(1):27-37.

16. Fewtrell L, Kaufmann RB, Kay D, Enanoria W, Haller L, Colford JM Jr. Water, sanitation, and hygiene interventions to reduce diarrhoea in less developed countries: a systematic review and meta-analysis. Lancet Infect Dis. 2005; 5(1):42-52.

17. Shamshiri S, Jafari R, Soltani S, Ramezani N. Dust detection and mapping in Kermanshah province using MODIS satellite imagery. Iran J App Ecol. 2014; 3(8):29-42.

18. Soleimani Z, Goudarzi G, Naddafi K, Sadeghinejad B, Latifi SM, Parhizgari N, et al. Determination of culturable indoor airborne fungi during normal and dust event days in Ahvaz, Iran. Aerobiologia. 2013;29(2):279-90.

19. Goudarzi G, Daryanoosh S, Godini H, Hopke P, Sicard P, De Marco A, et al. Health risk assessment of exposure to the Middle-Eastern dust storms in the Iranian megacity of Kermanshah. Public Health. 2017;148(9):109-16.

20. Kermanshah Meteorological Administration. Administration KM. Applied and daily statistics. 2017 [05-June-2018] http://www.kermanshahmet.ir/met_sta te.aspx?lang=fa-ir.

21. Bakhtyari S, Dehghani-zadeh M, Rayati A. Productive and non-productive entrepreneurship role in economic development. J Plann Budget. 2012; 17(3):131-59.

22. Mihai F, Grozavu A. Rural waste disposal issues within urban borders. 18th International multidisciplinary scientific GeoConference on ecology, economics, education and legislation SGEM 2018, conference proceedings, Albena, Bulgaria. 2018, pp.761-768. (hal-01838486).

23. Mihai F-C, Grozavu A. Role of waste collection efficiency in providing a cleaner rural environment. Sustainability. 2019;11(23):6855.

24. Sulaimany A, Masum MG, Riahi V. The development level of health indicators in Kermanshah province from the perspective of social justice in 2010. J Kerman Univ Med Sci. 2014;17(10):647-56.

25. Mousavi S, Seyedin S, Aryankhesal A, Sadeghifar J, Armoun B, Safari Y, et al. Stratification of Kermanshah province districts in terms of health structural indicators using scalogram model. J Health Promot Manage. 2013;2(2):7-15.

26. Shojaei P, Ghanbarzadegan A, Najibi M, Bastani P. Ranking of Iranian provinces based on healthcare infrastructures: before and after implementation of health transformation plan. Cost Effect Resour Allocation. 2020;18(1):4
27. Salimi M. A model to identify and interpret sport places per capita according to distribution of thiessen networks in GIS space. J Sport Manag. 2017:8(6):875-90.

28. Tan PY, Samsudin R. Effects of spatial scale on assessment of spatial equity of urban park provision. Landsc Urban Plan. 2017;158(8):139-54.

29. Zarei B, Khodamoradpoor M, Rezaei S. Designing the students sports development strategy in Kermanshah University. Eur J Phys Educ Sport Sci. 2017:3(6):72-84.

30. Oh K, Jeong S. Assessing the spatial distribution of urban parks using GIS. Landsc Urban Plan. 2007;82(1):25-32.

31. Khakpor B, Kazemibiniaz M, Asadi A, Razavi M. Analysis of urban green space and the optimal location using raster calculator (case study: 3RD Mashhad Municipality Zone). J Environ Sci Technol. 2015;17(2):117-29.

32. Tajdar V, Rafieian M, Taghvaee AA. An analysis and assessment of health index in Mashad metropolis with focus of urban planning approach. Honarhaye - Ziba-Memari-Va-Shahrsazi. 2010;2(41):101-11.

33. Jarvis I, Gergel S, Koehoorn M, van den Bosch M. Greenspace access does not correspond to nature exposure: measures of urban natural space with implications for health research. Landsc Urban Plan. 2020;194:103686.

34. Ariza-Villaverde AB, Jiménez-Hornero FJ, De Ravé EG. Influence of urban morphology on total noise pollution: multifractal description. Sci Total Environ. 2014:472(2):1-8.

35. Hammer MS, Swinburn TK, Neitzel RL. Environmental noise pollution in the United States: developing an effective public health response. Environ Health Perspect. 2014;122(2):115-9.

36. Dursun S, Ozdemir C, Karabork H, Koçak S. Noise pollution and map of Konya city in Turkey. J Int Environ Appl Sci. 2006;1 (1):63-72.

37. Nastaran M, Abolhassani F, Bakhtiari N. Spatial distribution of development indexes in Iranian cities using combinational ranking. J Reg Plann. 2015; 5(17):1-14.

38. Subica AM, Brown BJ. Addressing health disparities through deliberative methods: citizens' panels for health equity. Am J Public Health. 2020;110(2): 166-73.

39. Oraro-Lawrence T, Wyss K. Policy levers and priority-setting in universal health coverage: a qualitative analysis of healthcare financing agenda setting in Kenya. BMC Health Serv Res. 2020;20(1):1-11.

40. Rezaei S, Ghazanfari S, Kazemi Z, Karyani AK. Access to healthcare facilities: case study of Kermanshah province. J Kerman Univ Med Sci. 2014;18(7):416-25.

\section{Publisher's Note}

Springer Nature remains neutral with regard to jurisdictional claims in published maps and institutional affiliations.

\section{Submit your manuscript to a SpringerOpen ${ }^{\circ}$ journal and benefit from:}

- Convenient online submission

- Rigorous peer review

- Open access: articles freely available online

High visibility within the field

- Retaining the copyright to your article

Submit your next manuscript at $>$ springeropen.com 